\title{
Stage II
}

National Cancer Institute

\section{Source}

National Cancer Institute. Stage II. NCI Thesaurus. Code C28054.

Invasive cancer more extensive than stage I, usually involving local lymph nodes without spread to distant anatomic sites. 